Original Article

\title{
DOSE-DEPENDENT AMELIORATION OF EPIGALLOCATECHIN-3-GALLATE AGAINST SODIUM VALPROATE INDUCED AUTISTIC RATS
}

\author{
PALANISAMY KUMARAVEL ${ }^{1 *}$, GABRIEL MELCHIAS ${ }^{2}$, NAYAGAM VASANTH ${ }^{3}$, TAMILARASAN MANIVASAGAM ${ }^{4}$ \\ ${ }^{1 *}$ Department of Biotechnology, St. Joseph's College (Autonomous), Tiruchirappalli, Tamil Nadu, India, 2,3Department of Botany, St. \\ Joseph's College (Autonomous), Tiruchirappalli, Tamil Nadu, India, ${ }^{4}$ Department of Biochemistry and Biotechnology, Annamalai \\ University, Chidambaram, Tamil Nadu, India \\ Email: kumaravelbiotech@gmail.com
}

Received: 24 Jan 2017 Revised and Accepted: 02 Mar 2017

\begin{abstract}
Objective: Autism is a neurodevelopment related disorder with a range of clinical presentations attending serious behavioral and neurological disorders among young children that now occur at epidemic rates in developing countries, India included. The objective of this research was to study the effect of epigallocatechin gallate (EGCG) on sodium valproate-induced autism rats.

Methods: On the $12^{\text {th }}$ day of gestation wistar rats were administered with a single intraperitoneal injection of sodium valproate (VPA) (600 mg/kg body weight), which induced autism. The rats were treated with EGCG in varying doses 1,2 and 5 mg/kg body weight via oral administration. The neuroprotectivity effect of the EGCG was followed by assessing the neurotransmitters and neurobiochemical activities such as serotonin, glutamate and nitrite levels in hippocampus and cerebellum region of the brain.

Results: Early prenatal exposure to VPA provokes autistic symptoms. Induction of autism significantly impinged the neurotransmitters and neurochemicals such as serotonin, glutamate and nitrite levels in the brain (hippocampus and cerebellum) increased significantly in the rats exposed to VPA. After treatment with an effective dose of EGCG $2 \mathrm{mg} / \mathrm{kg}$ body weight the neurotransmitters and neurochemicals levels were decreased when compared with control and VPA-exposed rats.
\end{abstract}

Conclusion: EGCG ameliorates and reverses autistic attributes possibly due to its neuroprotective activity which could pave the way for future investigation for the possible therapeutic approach.

Keywords: Autism, Neurotransmitters, VPA, EGCG

(C) 2017 The Authors. Published by Innovare Academic Sciences Pvt Ltd. This is an open access article under the CC BY license (http://creativecommons.org/licenses/by/4.0/) DOI: http://dx.doi.org/10.22159/ijpps.2017v9i4.17283

\section{INTRODUCTION}

Autism is a devastating neurodevelopmental disorder in modern days with core symptoms of impaired social interactions, deficits in verbal and non-verbal communication, and sometimes self-injurious behaviors [1]. It is increasing rapidly in India in the ratio of 1:88 children due to increased exposure of environmental insults such as thalidomide, ethanol, and valproic acid due to increased stress during critical periods of neuronal development especially among genetically predisposed children [2]. VPA is on the market as an anticonvulsant since 1974 and is used in many countries because of its efficiency against several types of epilepsy. Exposing pregnant rats to VPA has been reported to result in abnormalities in the frontal, parietal, and temporal lobes of the cerebral cortex, cerebellum, and hippocampal anomalies associated with autism $[3,4]$.

Neurotransmitters, the neuronal signaling molecules play an important role in the normal development of the brain and are also important for maintaining functions such as memory, learning, behaviour, motor activity, etc. Neurotransmitter-mediated signaling is initiated by binding of specific neurotransmitters to its receptor proteins on the postsynaptic membrane, the number of which varies for each neurotransmitter. Biochemical studies have focused on neurotransmitters such as serotonin, norepinephrine, and $\gamma$-amino butyric acid (GABA), glutamate and ubiquitin. Serotonin (5hydroxytryptamine, $5 \mathrm{HT}$ ) is a inhibitory neurotransmitter monoamine derived from tryptophan. Serotonergic neurones innervate virtually all parts of the central nervous system, but, like all monoamines, are most concentrated in the brainstem. It is responsible for regulating learning, memory, sensory perception, noise sensitivity, behaviour, sleep and appetite [5-7]. So it is a key brain chemical, identified in the physiological abnormalities in autism spectrum disorders (ASD).

Green tea, the second most consumed beverage all over the world after water, is characterised by being rich (30\% of dry weight) in polyphenols. These polyphenols consist of four main components: $(-)$ epicatechin (EC), (-)-epicatechin gallate (ECG), (-)-epigallocatechin (EGC), and (-)-epigallocatechin gallate (EGCG) [8]. EGCG is a major component of green tea polyphenols which improves the bioavailability for the treatment of cancer [9], parkinson's disease [10], alzheimer's disease [11] and diabetes mellitus [12]. Till date, there is no specific treatment for autism. Currently available treatments mainly aim at symptomatic relief. Hence there is a need to find therapeutic drugs. We report on the effect of EGCG on VPA-induced neurobiochemical alterations in autistic rats.

\section{MATERIALS AND METHODS}

\section{Chemicals and reagents}

VPA and EGCG were purchased from Sigma-Aldrich (St. Louis, MO, USA). All other chemicals and reagents used were of analytical grade obtained from Himedia laboratory Ltd., Mumbai, India. EGCG was administered orally by every day at the dose of 1,2 and $5 \mathrm{mg} / \mathrm{kg}$ body weight (b.w.)

\section{Induction of Autism}

All the animals (Wistar rats) were fed with the standard pellet diet (Hindustan Lever Ltd., Bangalore, India) and water was made available ad libitum. Food and water were replenished daily. The animals were housed in polycarbonate cages in a room with a $12 \mathrm{~h}$ day-night cycle, the temperature of $22 \pm 2{ }^{\circ} \mathrm{C}$ and humidity of $45-64 \%$. The experimental protocol was approved by the committee for research and animal ethics, Esma institute of technology laboratory, Karur (Vide No: DIC (2008/33/014/00049/BEYA/TN/1695(BSS)/2014) and were in accordance with the guidelines of Indian Council of Medical Research (ICMR) [7].

On the $12^{\text {th }} \mathrm{d}$ of gestation, female rats were divided into two groups. 
Group I: Treated: Received a single intraperitoneal injection of VPA $600 \mathrm{mg} / \mathrm{kg}(\mathrm{n}=12)$.

Group II: Control: Received physiological saline $(n=12)$.

VPA was dissolved in saline at concentrations of $250 \mathrm{mg} / \mathrm{ml}$ [6]. Both VPA-treated and controlled female rats were housed individually and allowed to raise their own litters. The offspring is weaned on postnatal day (PND 20) and rats of either sex housed separately. Experiments are carried out only on male offspring.

\section{Experimental design}

On PND 20, male pups were divided into Eight groups $(n=6)$.

Group 1 (Control): Normal offspring received saline PND 21-90.

Group 2 (EGCG $1 \mathrm{mg} / \mathrm{kg}$ ): Normal offspring received EGCG PND 21-90.

Group 3 (EGCG 2 mg/kg): Normal offspring received EGCG PND 21-90.

Group 4 (EGCG 5 mg/kg): Normal offspring received EGCG PND 21-90.

Group 5 (VPA): Autistic offspring received normal saline from PND 21-90.

Group 6 (VPA+EGCG $1 \mathrm{mg} / \mathrm{kg}$ ): Autistic offspring received EGCG from PND 21-90.

Group 7 (VPA+EGCG $2 \mathrm{mg} / \mathrm{kg}$ ): Autistic offspring received EGCG from PND 21-90.

Group 8 (VPA+EGCG $5 \mathrm{mg} / \mathrm{kg}$ ): Autistic offspring received EGCG from PND 21-90.

Animals were sacrificed on PND 90 by cervical dislocation and brains were isolated on ice and weighed.

\section{Neurotransmitters and neurobiochemical parameters}

\section{Serotonin}

The hippocampus and cerebellum were separated from brains were isolated on ice and $100 \mathrm{mg}$ of tissue was homogenized with $5 \mathrm{ml}$ of acidified butanol $(0.68 \mathrm{ml}$ of $0.01 \mathrm{~N}$ Hydrochloric acid $(\mathrm{HCl}))$. After centrifugation for $5 \mathrm{~min}$ at $3,000 \mathrm{rpm}, 2.5 \mathrm{ml}$ supernatant was pipetted into a glass tube and shaken mechanically for 5 min with 5 $\mathrm{ml}$ of $\mathrm{n}$-heptane and $0.4 \mathrm{ml}$ of $0.1 \mathrm{~N} \mathrm{HCl}$. The phases were separated by centrifugation as before. To determine 5-HT, $0.4 \mathrm{ml}$ aliquots of the aqueous phase were pipetted into test tubes and $2.4 \mathrm{ml} 0.004 \%$ o-phthalaldehyde (OPT) in $10 \mathrm{~N} \mathrm{HCl}$ was added.

It was kept for heating in boiling water bath $15 \mathrm{~min}$. The tubes were cooled in water and fluorescence was measured using spectrofluorometer. Activation and fluorescent wavelengths were 360 and $470 \mathrm{~nm}$ respectively. Blanks were prepared by reacting $0.6 \mathrm{ml}$ of the OPT solution with $0.1 \mathrm{~N} \mathrm{HCl}$. Standards were prepared with $60 \mu \mathrm{g} / \mathrm{ml}$ in deionized water, diluted 1:100 for use with $0.1 \mathrm{~N} \mathrm{HCl}$ containing and $0.1 \mathrm{ml}$ reacted with $0.6 \mathrm{ml}$ of $0.004 \%$ OPT in $\mathrm{HCl}$ solution $[13,14]$.

\section{Nitrite}

Nitrite levels estimation is a measure of nitric oxide produced. The brain tissues (hippocampus and cerebellum) was weighed and homogenized in $50 \mathrm{mmol} / \mathrm{l}$ potassium phosphate buffer $(\mathrm{pH}$ 7.8) and centrifuged at $11,000 \mathrm{~g}$ for $15 \mathrm{~min}$ at $4^{\circ} \mathrm{C} .200 \mu \mathrm{l}$ of supernatant was mixed with $200 \mu \mathrm{l}$ saturated vanadium trichloride in $1 \mathrm{~N} \mathrm{HCl}$ and immediately $200 \mu \mathrm{l}$ Griess reagent $(0.1 \%$ $\mathrm{N}$-(1-naphthyl) ethylene diamide dihydrochloride, $1 \%$ sulfanilamide in $5 \%$ phosphoric acid) were added and mixed with it, and incubated at $37^{\circ} \mathrm{C}$ for $30 \mathrm{~min}$. The absorbance was measured at $540 \mathrm{~nm}$ using autoanalyzer. The concentration was calculated from a standard curve of potassium nitrite and expressed as micromoles of nitrate/nitrite $[15,16]$.

\section{Glutamate}

The weighed brain tissues (hippocampus and cerebellum) were taken in ice cold $10 \%$ tirchloro acetic acid and homogenized. The homogenate was then centrifuged at $10,000 \mathrm{~g}$ for $10 \mathrm{~min}$ at $0^{\circ} \mathrm{C}$. An aliquot $(0.1 \mathrm{ml})$ of the tissue extract was taken in $0.2 \mathrm{ml}$ of $0.014 \mathrm{M}$ ninhydrin solution in $0.5 \mathrm{M}$ carbonate-bicarbonate buffer. This was kept in a water bath at $60^{\circ} \mathrm{C}$ for $30 \mathrm{~min}$. The tubes were then cooled and treated with $5 \mathrm{ml}$ of alkaline copper tartrate reagent. After 10 min, the fluorescence was read at 377/451 (excitation/emission) in a spectrofluorometer. The amount of glutamate was expressed $\mu \mathrm{mole} / \mathrm{g}$ of tissue [17].

\section{Statistical analysis}

The data were subjected to one-way analysis of variance followed by Duncan's multiple range test (DMRT) using SPSS software 12.0. Results were expressed as mean $\pm S D$ for six rats in each group. $P$ values $<0.05$ were considered significant.

\section{RESULTS}

Administration of VPA on the $12^{\text {th }} \mathrm{d}$ of gestation induced autism manifested by the following neurotransmitters. VPA exposure induces neurobiochemical alterations such as an increase in serotonin (5-HT) levels in both hippocampus and cerebellum abnormalities when compared with control rats on PND 90, these alternations have been considered to support the validity of the rat model of autism, because serotonin is the key neurotransmitter for autism induction. On treatment with EGCG ( $2 \mathrm{mg} / \mathrm{kg}$ body weight), there was a significant reduction in their serotonin levels as compared to other doses $(1 \mathrm{mg} / \mathrm{kg}$ and $5 \mathrm{mg} / \mathrm{kg}$ body weight) in hippocampus and cerebellum regions of the brain in VPA-exposed rats (table 1).

Table 2 represents the induction of autism by VPA significantly $(\mathrm{p}<0.05)$ increased total nitrite levels compared to control group. Treatment with EGCG (2 mg/kg body weight) VPA-exposed rats significantly reversed the total nitrite $(p<0.05)$, levels compared to other doses $(1 \mathrm{mg} / \mathrm{kg}$ and $5 \mathrm{mg} / \mathrm{kg}$ body weight) in the brain (hippocampus and cerebellum).

Table 1: Effect of EGCG on serotonin in rats prenatally exposed to VPA

\begin{tabular}{lll}
\hline Groups & \multicolumn{2}{l}{ Brain tissue $(\boldsymbol{\mu g} / \mathbf{g}$ of tissue) } \\
\cline { 2 - 3 } & Hippocampus & Cerebellum \\
\hline Normal Control & $0.48 \pm 0.05$ & $044.50 \pm 24.34$ \\
EGCG $(1 \mathrm{mg} / \mathrm{kg})$ & $0.47 \pm 0.04$ & $045.61 \pm 24.10$ \\
EGCG $(2 \mathrm{mg} / \mathrm{kg})$ & $0.46 \pm 0.03$ & $045.53 \pm 24.00$ \\
EGCG $(5 \mathrm{mg} / \mathrm{kg})$ & $0.45 \pm 0.03$ & $044.10 \pm 23.21$ \\
VPA Control $(250 \mathrm{mg} / \mathrm{kg})$ & $0.97 \pm 0.09^{\mathrm{a}}$ & $110.50 \pm 28.42^{\mathrm{a}}$ \\
VPA $(250 \mathrm{mg} / \mathrm{kg})+E G C G(1 \mathrm{mg} / \mathrm{kg})$ & $0.87 \pm 0.07^{\mathrm{b}}$ & $090.12 \pm 25.62^{\mathrm{b}}$ \\
VPA $(250 \mathrm{mg} / \mathrm{kg})+E G C G ~(2 \mathrm{mg} / \mathrm{kg})$ & $0.63 \pm 0.06^{\mathrm{b}}$ & $065.12 \pm 24.98^{\mathrm{b}}$ \\
VPA $(250 \mathrm{mg} / \mathrm{kg})+E G C G(5 \mathrm{mg} / \mathrm{kg})$ & $0.77 \pm 0.07^{\mathrm{b}}$ & $079.12 \pm 24.99^{\mathrm{b}}$ \\
\hline
\end{tabular}

Each column is mean \pm SD for six rats in each group. Significance was determined by one-way ANOVA followed by DMRT. aP $<0.05$ versus normal control, $\mathrm{b} P<0.05$ versus VPA control. 
Table 2: Effect of EGCG on nitrite levels in rats prenatally exposed to VPA

\begin{tabular}{lll}
\hline Groups & Brain tissue $(\boldsymbol{\mu m o l} / \mathbf{g}$ of tissue) & Cerebellum \\
\cline { 2 - 3 } & Hippocampus & $090.51 \pm 4.5$ \\
Normal Control & $069.72 \pm 3.99$ & $069.67 \pm 4.4$ \\
EGCG $(1 \mathrm{mg} / \mathrm{kg})$ & $068.98 \pm 3.98$ & $088.34 \pm 4.4$ \\
EGCG $(2 \mathrm{mg} / \mathrm{kg})$ & $068.83 \pm 3.98$ & $088.17 \pm 4.3$ \\
EGCG $(5 \mathrm{mg} / \mathrm{kg})$ & $122.20 \pm 8,34^{\mathrm{a}}$ & $140.08 \pm 6.2^{\mathrm{a}}$ \\
VPA Control $(250 \mathrm{mg} / \mathrm{kg})$ & $090.11 \pm 6.57^{\mathrm{b}}$ & $120.86 \pm 5.3^{\mathrm{b}}$ \\
VPA $(250 \mathrm{mg} / \mathrm{kg})+E G C G(1 \mathrm{mg} / \mathrm{kg})$ & $075.67 \pm 4.31^{\mathrm{b}}$ & $098.83 \pm 4.9^{\mathrm{b}}$ \\
VPA $(250 \mathrm{mg} / \mathrm{kg})+E G C G(2 \mathrm{mg} / \mathrm{kg})$ & $085.43 \pm 4.99^{\mathrm{b}}$ & $110.61 \pm 4.8^{\mathrm{b}}$ \\
VPA $(250 \mathrm{mg} / \mathrm{kg})+E G C G(5 \mathrm{mg} / \mathrm{kg})$ & & \\
\hline
\end{tabular}

Each column is mean \pm SD for six rats in each group. Significance was determined by one-way ANOVA followed by DMRT. aP $<0.05$ versus normal control, bP<0.05 versus VPA control.

Altered hippocampal and cerebellum glutamate levels were measured on PND 90. VPA rats had shown significantly increased glutamate levels in hippocampus and cerebellum compared to control group. EGCG (2 $\mathrm{mg} / \mathrm{kg}$ body weight) treatment partially decreased glutamate level in the brain (hippocampus and cerebellum) when compared with other doses ( $1 \mathrm{mg} / \mathrm{kg}$ and $5 \mathrm{mg} / \mathrm{kg}$ body weight) in VPA-induced autistic rats (table 3).

Table 3: Effect of EGCG on glutamate levels in rats prenatally exposed to VPA

\begin{tabular}{lll}
\hline Groups & Brain tissue ( $\boldsymbol{\mu m o l} / \mathbf{g}$ of tissue) & Cerebellum \\
\cline { 2 - 3 } & Hippocampus & $12.65 \pm 0.49$ \\
Normal Control & $10.23 \pm 0.33$ & $12.23 \pm 0.48$ \\
EGCG $(1 \mathrm{mg} / \mathrm{kg})$ & $10.19 \pm 0.33$ & $12.34 \pm 0.47$ \\
EGCG $(2 \mathrm{mg} / \mathrm{kg})$ & $10.17 \pm 0.32$ & $12.33 \pm 0.47$ \\
EGCG $(5 \mathrm{mg} / \mathrm{kg})$ & $10.18 \pm 0.32$ & $16.45 \pm 0.21^{\mathrm{a}}$ \\
VPA Control $(250 \mathrm{mg} / \mathrm{kg})$ & $17.20 \pm 0.16^{\mathrm{a}}$ & $15.82 \pm 0.33^{\mathrm{b}}$ \\
VPA $(250 \mathrm{mg} / \mathrm{kg})+E G C G(1 \mathrm{mg} / \mathrm{kg})$ & $15.11 \pm 0.29^{\mathrm{b}}$ & $12.67 \pm 0.25^{\mathrm{b}}$ \\
VPA $(250 \mathrm{mg} / \mathrm{kg})+E G C G(2 \mathrm{mg} / \mathrm{kg})$ & $14.43 \pm 0.26^{\mathrm{b}}$ & $14.23 \pm 0.35^{\mathrm{b}}$ \\
VPA $(250 \mathrm{mg} / \mathrm{kg})+E G C G(5 \mathrm{mg} / \mathrm{kg})$ & & $15.35 \pm 0.36^{\mathrm{b}}$ \\
\hline
\end{tabular}

Each column is mean \pm SD for six rats in each group. Significance was determined by one-way ANOVA followed by DMRT. aP $<0.05$ versus normal control, $\mathrm{b}<<0.05$ versus VPA control.

\section{DISCUSSION}

Autism is a neurological developmental disorder defined by the presence of a triad of communication, social and stereotypical behavioural characteristics with onset before $3 \mathrm{y}$ of age in children. The development of the human brain is a series of precisely timed events which results in neural circuits. The circuits are critical in the integration of sensory information in cognitive functions and movements [18]. The neurotransmitters and the neuropeptides not only play an important role in the function of neuronal circuits but they are also involved in the regulation of the neuronal development of these structures. They appear in the embryos before the neurons are differentiated and change their role during the brain development [19].

In our present study prenatal exposure to VPA evokes changes in some neurotransmitters and neurochemicals such as serotonin, glutamate and nitric oxide levels were increased, nearly every area of the brain has been shown to abnormalities have been found in autistic brain and the regions are frontal, parietal, temporal lobes of the cerebral cortex and the cerebellum [20]. The cerebellum has long been considered of primary importance to the initiation of movements, coordination, sensory and learning [21]. Serotonin regulates several aspects of brain development, including regulation of cell division, differentiation, neurite outgrowth and synaptogenesis. Earlier reports VPA rats had shown increased serotonin levels in the hippocampus [6]. Early abnormality of the 5HT system might be followed by postnatal abnormalities such as abnormal 5-HT concentration and abnormal neural network formation [21]. In our present study EGCG treatment partially decreased hippocampus and cerebellum serotonin levels. It may attribute to up-regulated serotonin transporter (SERT) expression that enhances the reuptake of released serotonin [22].

Hippocampal glutamate aids uptake from rats after prenatal exposure to VPA, with a significant increase in glutamate uptake at
P120. Glutamate signaling defects causing an imbalance in excitatory and inhibitory neuronal circuits are implicated in autism; were found to cause abnormal trafficking of $\alpha$-amino-3-hydroxy-5methyl-4-isoxazolepropionic acid (AMPA) receptor receptors in neurons. AMPA is a non-NMDA (N-methyl-D-aspartate receptor) type ionotropic trans membrane receptor for glutamate that mediates fast synaptic transmission in the central nervous system (CNS). EGCG modulates AMPA receptor functions in the VPA exposed rats. These results will provide valuable insights into the regulatory mechanisms of neurotransmitters and social behaviors and guide the development of novel AMPA receptor-based therapies to correct social deficits in autism [23-26]. EGCG significantly reduced delayed neuronal damage and it has been demonstrated to pass the blood-brain barrier and reach brain parenchyma in an animal study [27], shows a significant increase in the number of surviving neurons in the hippocampal region [28].

In the present study, increased total nitrite levels indicate the involvement of oxidative stress in VPA-induced autism. Nitric oxideinduced cell death in the nervous system is a major concern in conditions such as brain ischemia, neurodegeneration and inflammation [29]. Treatment with EGCG significantly reversed the altered oxidative stress markers in hippocampal and cerebellum brain region, due to its antioxidant properties exert to scavenge Reactive oxygen species (ROS) would have played a major role in preserving the antioxidant system $[30,31]$.

\section{CONCLUSION}

In the present study, we found administration of VPA on the $12^{\text {th }} \mathrm{d}$ of gestation significantly inducing autism. Oral administration of EGCG significantly protects the autism by maintaining the neurotransmitters and neurochemicals in the brain. These effects could be due to its potent antioxidant and also good radical scavenging; in addition to its ability to invoke a range of cellular 
mechanisms it modulates signaling pathways in the neurotransmitters of hippocampus and cerebellum.

\section{ACKNOWLEDGMENT}

Authors are thankful to Esma institute of technology, Karur and Dr. T. Manivasgam, Annamalai University for providing necessary assistance.

\section{CONFLICT OF INTERESTS}

Declared none

\section{REFERENCES}

1. Bauman ML, Kemper TL. Histoanatomic observations of the brain in early infantile autism. Neurology 1985;35:866-874.

2. Rodier PM, Ingram JL, Tisdale B, Croog VJ. Linking etiologies in humans and animal models: studies of autism. Reprod Toxicol 1997:11:417-422.

3. Ingram JL, Peckham SM, Tisdale B, Rodier PM. Prenatal exposure of rats to valproic acid reproduces the cerebellar anomalies associated with autism. Neurotoxicol Teratol 2000,22:319-324.

4. George C. Wagner, Kenneth R. Reuhl, Michelle Cheh, Paulette McRae, Alycia K. Halladay. A new Neurobehavioral model of autism in mice: Pre and postnatal Exposure to sodium valproate. J Autism Dev Disord 2006;36:779-793.

5. Hossein Fatemi S, Amelia, Merz, George, Realmuto. The roles of reelin, $\mathrm{bcl}_{2}$, and serotonin in cerebellar pathology in autism. J Develop Phys Disab 2003;15:1-22.

6. Sandhya T, Sowjanya J, Veeresh B. Bacopa monniera (L.) Wettst Ameliorates behavioral alterations and oxidative markers in sodium valproate-induced Autism in Rats. Neurochem Res 2012;37:1121-1131.

7. Kumaravel P, SubashS, Seethalakshmi KS, Murugan N, YuvarajanR, Subramanian P. Monosodium glutamate modulates the circadian rhythms of biochemical variables and behavioral activity in rats under constant light. Int J Nutr Pharmacol Neurol Dis 2012;2:251-257.

8. Guo S, Yan J, Yang T, Yang X, Bezard E, Zhao B. Protective effects of green tea polyphenols in the 6-OHDA rat model of Parkinson's disease through inhibition of ROS-NO pathway. Biol Psychiatry 2007;62:1353-1362.

9. Elena Lecumberri, Yves Marc Dupertuis, Raymond Miralbell, Claude Pichard. Green tea polyphenol EGCG as an adjuvant in cancer therapy. Clin Nutr2013;32:894-903.

10. Ji Seon Kim, Jong-Min Kim, Jeong-Ja O, Beom S. Jeon. Inhibition of inducible nitric oxide synthase expression and cell death by EGCG, a green tea catechin, in the 1-methyl-4-phenyl-1,2,3,6tetrahydropyridine mouse model of Parkinson's disease. J of Clin Neuro 2010;17:1165-1168.

11. Adam Smith, Brian Giunta, Paula C. Bickford, Michael Fountain, Jun Tan, R. Douglas Shytle. Nanolipidic particles improve the bioavailability and secretase inducing ability of EGCG for the treatment of Alzheimer's disease. Intr J Pharm 2010;389:207-212.

12. Tourandokht B, Mehrdad R. Chronic epigallocatechin-3 gallate ameliorates learning and memory deficits in diabetic rats via modulation of nitric oxide and oxidative stress. Behav Brain Res 2011;224:305-310.

13. Maickel RP, Cox RH, Saillant J, Miller FP. A method for the determination of serotonin and norepinephrine in discrete areas of rat brain. Int J Neuropharmacol 1968;7:275-281.

14. Jacobowitz DM, Richardson JS. A method for the rapid determination of norepinephrine, dopamine and serotonin in the same brain region. Pharmacol Biochem Behav 1978;8:515-519.
15. Green LCDA, Wagner DA. Analysis of nitrate, nitrite and [15 N] nitrate in biological fluids. Anal Biochem 1982;126:131-138.

16. Tsikas D. Analysis of nitrite and nitrate in biological fluids by assays based on the Gries reaction: an appraisal of the Gries reaction in the L-arginine/nitric oxide area of research. J Chromatogr B Anal Technol Biomed Life Sci 2007;851:51-70.

17. Lowe IP, Robins E, Eyermann GJ. The fluorometric measurement of glutamic decarboxylase and its distribution in the brain. J Neurochem 1958;3:8-18.

18. Berger-Sweeney J, Meadows K, Mills J, Hohmann CF. Gender differences in the effect of neonatal basal forebrain lesions on spatial navigation. Soc Neurosci Abstr 1993;19:1233.

19. Barbara S. Mesmere. New Autism Research Developments. Newyork: Nova Science Publishers; 2007. p.29-46.

20. Bauman NL and Kemper TL, Neuroanatomic observations of the brain in autism, in the neurobiology of autism. Baltimore, Md, USA, Johns Hopkins University Press; 1994. p. 119-145.

21. Schmahmann JD. The cerebellum and cognition. San Diego, Academic Press; 1997. p. 665.

22. Miyazaki K, Narita N, Narita M. Maternal administration of thalidomide or valproic acid causes abnormal serotonergic neurons in the offspring: implication for pathogenesis of autism. Int J Dev Neurosci 2005;23:287-297.

23. Charles PD, Ambigapathy G, Geraldine P, Akbarsha MA, Rajan KE. Bacopa monniera leaf extract up-regulates tryptophan hydroxylase (TPH2) and serotonin transporter (SERT) expression: Implications in memory formation. J Ethnopharmacol 2011;134:55-61.

24. Rebeca Mejias, Abby Adamczyk, Victor Anggono, Tejasvi Niranjan, Gareth M. Thomas, Kamal Sharma, et al. Gain-offunction glutamate receptor interacting protein 1 variants alter GluA2 recycling and surface distribution in patients with autism. Proc Natl Acad Sci 2011;108:4920-4925.

25. Roberta Bristot Silvestrin, Victorio Bambini-Junior, Fabiana Galland, Larissa Daniele Bobermim, Andre Quincozes Santos, Renata Torres Abib, et al. Animal model of autism induced by prenatal exposure to valproate: altered glutamate metabolism in the hippocampus. Brain Res 2013;1495:52-60.

26. Archana Panche, Sheela Chandra, Diwan AD, Sanjay Harke. Alzheimer's and current therapeutics: a review. Asian J Pharm Clin Res 2015;8:14-19.

27. Suganuma M, Okabe S, Oniyama M, Tada $Y$, Ito H. and Fujiki H. Wide distribution of [3H]-(2)-epigallocatechin gallate, a cancer preventive tea polyphenol, in mouse tissue. Carcinogenesis 1998;19:1771-1776.

28. Seong-Ryong Leea, Seong-Il Suhb, Sang Pyo Kimc. Protective effects of the green tea polyphenol (2)-epigallocatechin gallate against hippocampal neuronal damage after transient global ischemia in gerbils. Neurosci Lett 2000;287: 191-194.

29. Bolanos JP, Almeida A, Stewart V, Peuchen S, Land JM, Clark JB, et al. Nitric oxide-mediated mitochondrial damage in the brain: mechanisms and implications for neurodegenerative diseases. J Neurochem 1997;68:2227-2240.

30. Yang CS. Tea and health. Nutri 1999;15:946-949.

31. Sireesha K, Sailaja Rao P. Oxidative stress and diabetes: an overview. Asian J Pharm Clin Res 2015;8:15-19.

\section{How to cite this article}

- Palanisamy Kumaravel, Gabriel Melchias, Nayagam Vasanth, Tamilarasan Manivasagam. Dose-dependent amelioration of epigallocatechin-3-gallate against sodium valproate induced autistic rats. Int J Pharm Pharm Sci 2017;9(4):203-206. 